\title{
Penetrating keratoplasty in adults with congenital glaucomas
}

M Ramchandani, S Mohammed, S Mirza and PJ McDonnell

\begin{abstract}
Purpose To report the problems and outcomes of penetrating keratoplasty (PKP) in patients with corneal oedema due to congenital glaucoma.

Method Case note review of nine such consecutive patients treated with PKP. A Kaplan - Meir survival curve was plotted for the series.

Results Nine patients, ranging in age from 27 to 71 years at the time of their surgery were followed up for a mean of 28 months. All had undergone previous surgery for glaucoma. Preoperatively all patients had controlled intraocular pressures, and four were on ocular hypotensives. Two patients developed corneal graft failure at $\mathbf{1 5}$ and $\mathbf{4 1}$ months postoperative. Raised pressure was the cause in both. Final visual acuity improved in five patients, was the same in three, and deteriorated in only

the United Kingdom for patients with

keratoconus. Other common indications include corneal scarring due to herpetic keratitis and pseudophakic bullous keratopathy.

In patients with congenital glaucoma, the cornea may have Haab's striae running across the visual axis with relatively clear intervening corneal stroma, diffuse corneal oedema, or there may be associated corneal vascularization. The cornea may remain clear for many years into adulthood and later decompensate resulting from additional age-related attrition of endothelial cells. ${ }^{1}$

In addition to corneal opacification, adult patients with congenital glaucoma can have poor vision because of pre-existing glaucomatous damage, amblyopia, and lens opacity. Corneal surgery in these patients is infrequently performed. ${ }^{2}$ We assessed the role of PKP in improving vision in such patients.
\end{abstract} one. Complications included raised intraocular pressure, cataract, retinal detachment, and endophthalmitis secondary to an infected Molteno implant.

Conclusion Despite multiple impediments to good postoperative vision including previous surgery and pre-existing glaucomatous damage, a successful outcome was achieved by careful patient selection, and an awareness of, and meticulous attention to postoperative complications.

Eye (2004) 18, 703-708. doi:10.1038/sj.eye.6700754

Published online 23 January 2004

Keywords: penetrating keratoplasty; corneal; graft; glaucoma; congenital; buphthalmos

\section{Introduction}

Penetrating keratoplasty (PKP) has already been performed most successfully and frequently in

\section{Method}

Consecutive patients referred to the corneal clinic at the Birmingham and Midland Eye Centre since 1991 with congenital glaucoma who underwent PKP were selected. There were no exclusion criteria. Corneal surgery was performed by one surgeon, $\mathrm{PMcD}$. The case notes were reviewed and the results compared with the limited published literature. ${ }^{3} \mathrm{~A}$

Kaplan-Meir survival graph was plotted for the series (Figure 1).

\section{The procedure}

Stabilizing sutures through the inferior and superior recti supported the host eye. Calipers were used to determine the graft size required. Eight of the nine eyes had buphthalmos so the graft sizes were larger than usual for the
Birmingham and Midland Eye Centre

City Hospitals NHS Trust Birmingham, UK

Correspondence: PJ McDonnell Birmingham and Midland Eye Centre

City Hospital NHS Trust Dudley Rd Birmingham B18 7QH, UK Tel: + 441215543801 Fax: + 441215076773 E-mail: peter.mcdonnell@ cityhospbham.umids.nhs.uk

Received: 1 August 2002 Accepted: 6 May 2003 Published online: 23 January 2004

This work has received no funding. There are no proprietary interests. 
surgeon, $\mathrm{PMcD}$. One patient who had angle closure glaucoma had a small eye (Table 1).

The corneoscleral disc was placed on a stand with the endothelial side upwards. A sharp trephine blade of $0.25 \mathrm{~mm}$ larger than required for the graft bed was placed on the endothelial surface of the corneal disc. Firm and even pressure was used to drive the trephine through the disc in a single smooth movement. Saline was used to keep the surface moist.

A marker was used to indicate equally spaced radial positions on the host cornea. Then the host disc was removed using a hollow trephine of the required size with careful positioning for centration. Using a diamond knife, the host disc was removed completely. The anterior surface of the lens and iris were covered with a viscoelastic. Four 10/0 nylon interrupted sutures at 12, 3, 6 , and $9 \mathrm{O}^{\prime}$ clock were placed to fixate the graft. A continuous nylon 10/0 suture was used, and then the interrupted sutures were removed. Subconjunctival betamethasone $4 \mathrm{mg}$ and cefuroxime $125 \mathrm{mg}$, or gentamicin $10 \mathrm{mg}$ were administered at the end of the operation.

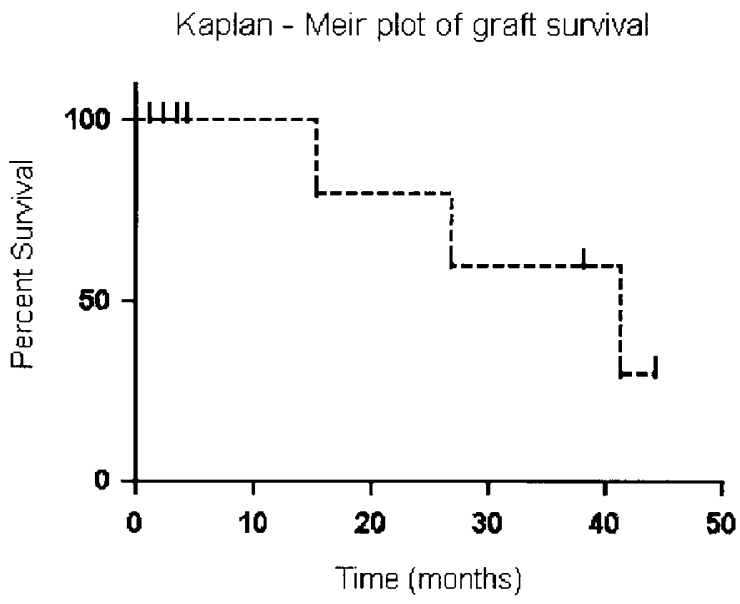

Figure 1 Kaplan-Meir plot of graft survival present series.

Table 1 Operative details

\begin{tabular}{llclc}
\hline Patient & $\begin{array}{l}\text { Phakic } \\
\text { state }\end{array}$ & $\begin{array}{c}\text { Donor } \\
\text { size }\end{array}$ & $\begin{array}{l}\text { Host } \\
\text { button }\end{array}$ & $\begin{array}{c}\text { Simultaneous } \\
\text { op }\end{array}$ \\
\hline 1 & Aphakic & 8.25 & 8 & - \\
2 & Pseudophakic & 7.25 & 7 & - \\
3 & Pseudophakic & 8 & 7.75 & - \\
4 & Phakic & 8.25 & 8 & ECCE + IOL \\
5 & Phakic & 7.75 & 7.5 & \\
6 & Phakic & 7.75 & 7.5 & ECCE + IOL \\
7 & Phakic & 6.75 & 6.5 & \\
8 & Phakic & 8.25 & 8 & ECCE + IOL \\
9 & Phakic & 8.25 & 8 & \\
\hline
\end{tabular}

\section{Results}

Of the nine patients included, there were four were men and five women, and all were Caucasian. They ranged from 23 to 71 years of age at the time of PKP with a mean age of 43.8 years. The left eye was involved in five and the right in four; see Table 2.

\section{Preoperative conditions}

Most patients had undergone multiple pressure-lowering procedures in the neonatal period or in childhood (Table 2); however, a variety of ocular surgical procedures were also performed in later life often preceding PKP by only a few years to a few months.

\section{Preoperative glaucoma control}

Of those patients in whom the preoperative intraocular pressure (IOP) control was inadequate on topical or systemic treatment, three (no. s 2, 5, and 8) required a Molteno drainage device to be inserted between 6 months and 3 years before grafting. In the last of these, the initial graft failed and the Molteno was revised a few months prior to repeat graft surgery. This patient also had cyclodiode laser 8 months prior to the regraft to control the preoperative pressure.

\section{Preoperative phakic state}

At the time of initial grafting, six patients were phakic, three of these had simultaneous extracapsular cataract surgery after removal of the host corneal button. Two patients underwent previous cataract extraction; patient 3,8 years before PKP and patient 1,3 years before PKP. This patient was rendered aphakic and went on to develop a retinal detachment. One patient (no. 2) had routine extracapsular cataract surgery 6 months after PKP, and in this case the graft failed.

\section{Visual outcome}

All grafts survived at 1 year, or at the longest follow-up when 1 year had not been reached. At this stage, compared to preoperative values the vision had improved in seven patients, and was the same in one and worse in one.

At final follow-up, the best corrected visual acuity (BCVA) improved in five patients, was the same in three, and worse in one. In the latter, the graft failed and regrafting resulted in an overall improvement in vision (Table 3). 
Table 2 Previous treatment

\begin{tabular}{|c|c|c|c|c|c|c|c|c|c|}
\hline \multirow[t]{2}{*}{ Patient } & \multirow[t]{2}{*}{ Gender } & \multirow[t]{2}{*}{ Age } & \multirow[t]{2}{*}{ Grafted eye } & \multicolumn{2}{|c|}{ Preoperative BCVA } & \multicolumn{2}{|c|}{ Previous surgery } & \multicolumn{2}{|c|}{ Preoperative medication } \\
\hline & & & & Right & Left & Right & Left & Right & Left \\
\hline 1 & M & 46.5 & $\mathrm{~L}$ & NPL & $6 / 24$ & Perforating eye injury & $\begin{array}{l}\text { Repeat drainage sx in childhood } \\
\text { Iridectomy aged } 31 \\
\text { Iridotomy aged } 33 \\
\text { ECCE - aphakia aged } 43\end{array}$ & - & $\mathrm{NaCl}$ \\
\hline 2 & M & 37.5 & $\mathrm{~L}$ & Enuc & $\mathrm{CF}$ & $\begin{array}{l}\text { Cyclodialysis }<1 \\
\text { Iridencleisis aged } 1 \\
\text { Enucleation aged } 26\end{array}$ & $\begin{array}{l}\text { Cyclodialysis \&lt1 } \\
\text { Iridencleisis aged } 1 \\
\text { Molteno aged } 37 \\
\text { ECCE }+ \text { IOL aged } 38\end{array}$ & & $\begin{array}{l}\text { Timolol } \\
\text { Pilocarpine } \\
\text { Diamox }\end{array}$ \\
\hline 3 & $\mathrm{M}$ & 58.9 & $\mathrm{~L}$ & $6 / 18$ & $6 / 18$ & Trabeculectomy aged $6 \mathrm{mths}$ & $\begin{array}{l}\text { Trabeculectomy aged } 6 \mathrm{mths} \\
\text { ECCE }+ \text { IOL aged } 50\end{array}$ & $\begin{array}{l}\mathrm{NaCl}, \text { Xalatan } \\
\text { Teoptic }\end{array}$ & $\begin{array}{l}\mathrm{NaCl}, \text { Xalatan } \\
\text { Teoptic }\end{array}$ \\
\hline 4 & $\mathrm{~F}$ & 71.3 & $\mathrm{R}$ & $\mathrm{HM}$ & Enuc & $\begin{array}{l}\text { Scleral puncture aged } 1 \\
\text { Trabeculectomy aged } 47\end{array}$ & Scleral puncture aged 1 Enucleation & Timolol & \\
\hline 5 & $F$ & 23.8 & $\mathrm{R}$ & $\mathrm{HM}$ & $6 / 36$ & $\begin{array}{l}\text { Molteno tube aged } 20, \\
\text { Trabeculectomy aged } 1\end{array}$ & $\begin{array}{l}\text { Trabeculectomy aged } 15 \\
\text { Trabeculectomy aged } 1\end{array}$ & $\begin{array}{l}\text { Diamox } \\
\text { Timolol, Pilocarpine }\end{array}$ & $\begin{array}{l}\text { Diamox } \\
\text { Timolol, Pilocarpine }\end{array}$ \\
\hline 6 & M & 23.8 & $\mathrm{~L}$ & NPL & $\mathrm{CF}$ & $\begin{array}{l}\text { Goniotomy aged } 1 \\
\text { Goniotomy aged } 2 \\
\text { Schies aged } 4\end{array}$ & $\begin{array}{l}\text { Goniotomy aged } 1 \\
\text { Schies aged } 4 \\
\text { Trabeculectomy aged } 8 \\
\text { Cryopexy aged } 10 \\
\text { Cryopexy aged } 11\end{array}$ & & Metiprolol \\
\hline 7 & $\mathrm{~F}$ & 63.9 & $\mathrm{R}$ & $\mathrm{HM}$ & Enuc & Trephining & Trephining, enucleation & Viscotears & \\
\hline 8 & $\mathrm{~F}$ & 41.2 & $\mathrm{~L}$ & Enuc & $\mathrm{HM}$ & Enucleation aged 33 & $\begin{array}{l}\text { Trabeculectomy childhood } \\
\text { Molteno aged } 30 \\
\text { PKP elsewhere } 32 \text { - failed } \\
\text { Cyclodiode } 40 \\
\text { Revision of Molteno, } 41 \text { years }\end{array}$ & - & $\begin{array}{l}\text { Diamox } \\
\text { Betagan } \\
\text { Pilocarpine } \\
\text { Alphagan } \\
\text { Maxidex }\end{array}$ \\
\hline 9 & $\mathrm{~F}$ & 27.3 & $\mathrm{R}$ & $\mathrm{CF}$ & NPL & $\begin{array}{l}\text { Drainage sx before } 5 \text { years } \\
\text { Trabeculectomy aged } 17\end{array}$ & Drainage sx before 5 years & $\mathrm{NaCl}$ & $\mathrm{NaCl}$ \\
\hline
\end{tabular}




\section{Pressure-related complications}

Patients 3 and 7 developed raised IOP postoperatively. Both were uncontrolled on medication and were referred to a glaucoma specialist. Patient seven required two episodes of cyclodiode laser treatment 1 month after surgery, and is on three topical hypotensives, compared to no glaucoma treatment preoperative. Her acuity remains unchanged from the preoperative value. Patient 3's IOP consistently measured $36 \mathrm{mmHg}$ using Goldman Tonometry from 2 weeks after PKP and did not respond to systemic acetazolamide. This was considered in part to be an inaccuracy in measurement and eventually normalized after 4 weeks on just Xalatan, Cosopt, and Alphagan.

Graft failure occurred in three patients (no. s 2, 5, and 6).

In patient 2 , this occurred at 15.3 months postoperative. He developed a cataract after the initial penetrating keratoplasty and underwent an extracapsular cataract extraction with lens implant 9.1 months following the initial surgery. The postoperative period was complicated by raised pressure and uveitis, and this was the cause of graft failure. As this was his only eye, he underwent a second graft procedure. Unfortunately, after 1.9 years this also failed because of raised IOP and he developed a vascularized cornea. Interestingly, his final visual outcome was not worse than that at the outset, but he now required more treatment: diamox, timolol, and predsol to control his IOP than preoperatively.

In patient 5 , the graft survived 41.4 months. The cause was again raised IOP. This patient underwent explorations of a Molteno implant shortly after the PKP and at 2 years after the graft. Unfortunately, 69 months after the graft surgery and after the graft had failed, he developed endophthalmitis secondary to infection of the Molteno implant. This was treated and his final vision was no worse than the preoperative value, although significantly worse than the best postgraft value before failure. He was on similar postoperative ocular hypotensive treatment to before the PKP.

Patient 6 developed band keratopathy and graft failure 26.8 months after the initial combined corneal graft and cataract extraction with lens implant. After 17 months, he underwent a second PKP using the same graft and host disc sizes of 7.75 and $7.5 \mathrm{~mm}$ diameter. After 92.2 months, this second graft was still functioning well and the vision one line better than before the initial surgery.

\section{Other complications}

These included a rhegmatogenous retinal detachment in an aphake (patient 1) at 38 months following PKP. This was treated successfully by the vitreo retinal surgeons by pneumoretinopexy in view of the buphthalmos and thin sclera. Patient 4, who underwent simultaneous extracapsular cataract extraction with lens implant, developed posterior capsular opacification and required YAG laser capsulotomy 18 months following initial surgery.

\section{Discussion}

\section{Planning PKP}

In the preoperative evaluation of such patients, it is important to identify risk factors for graft rejection or failure and poor IOP control. Inflammation of the eyelid margin, abnormal eyelid position, lagophthalmos, and trichiasis should be corrected before corneal surgery. Corneal anaesthesia, exposure, or severe tear deficiency markedly diminishes the likelihood of success. It is best to avoid operating on eyes with persistent intraocular inflammation, corneal or conjunctival infection, or persistent epithelial defects. Corneal vascularization and thinning, anterior iris synechiae, anterior chamber inflammation, and lens opacities should be noted. ${ }^{4}$ If the fundus cannot be adequately visualized, then B-scan ultrasonography is indicated. An electrodiagnostic test

Table 3 Complications and outcome

\begin{tabular}{|c|c|c|c|c|c|c|c|}
\hline Patient & $\begin{array}{c}\text { Preoperative } \\
\text { BCVA }\end{array}$ & Final $B C V A$ & Interval months & Complication & Interval & BCVA post regraft & Interval \\
\hline 1 & $6 / 24$ & $6 / 18$ & 38.1 & Retinal detachment & 38.0 & - & - \\
\hline 2 & $\mathrm{CF}$ & $2 / 60$ & 15.3 & Graft failed & 15.3 & $\mathrm{HM}$ & 17.25 \\
\hline 3 & $6 / 18$ & $6 / 18$ & 4.4 & Raised IOP & 0.5 & - & - \\
\hline 4 & $\mathrm{HM}$ & $6 / 18$ & 44.3 & Posterior capsule fibrosis & 18.0 & - & - \\
\hline 5 & HM & $\mathrm{HM}$ & 94.6 & Graft failed & 41.4 & - & - \\
\hline 6 & $\mathrm{CF}$ & $\mathrm{HM}$ & 41.7 & Graft failed & 41.7 & 660 & 92.16 \\
\hline 7 & $\mathrm{HM}$ & $\mathrm{HM}$ & 3.5 & Raised IOP & 1.0 & - & - \\
\hline 8 & $\mathrm{HM}$ & $6 / 18$ & 3.6 & None & - & - & - \\
\hline 9 & CF & $6 / 36$ & 1.8 & None & - & - & - \\
\hline
\end{tabular}


may be useful to determine whether surgery would be beneficial. In our series, four of the nine patients had such investigations.

Conjunctival scarring, previous glaucoma surgery, and the complexity of the preoperative hypotensive regime have a bearing on IOP control. In these cases, involvement of a glaucoma specialist skilled in a variety of surgical techniques in the planning stages for surgery is essential. Procedures to control the IOP should be performed first as this will enhance graft survival and reduce postoperative complications.

If there is coexisting cataract this must be taken into account in planning PKP. Not doing so may prevent the improvement in vision expected by the corneal surgery. In our series, those patients who underwent initial cataract surgery developed increasing corneal opacities necessitating PKP between 3 and 8 years later.

Conversely, the one patient who underwent cataract surgery after PKP developed graft failure. These findings suggest that initial cataract surgery exacerbates corneal decompensation and that further surgery after PKP is a risk for failure. Ideally then cataract surgery should be planned either before PKP or at the same time as PKP. In the latter there is the added benefit of only one corneal wound rather than two.

It is essential that there is appropriate patient selection for grafting. Whether keratoplasty is indicated depends upon the condition of the fellow eye, the presence of complicating conditions, and the patient or relative's ability to participate in care. Most in our study had severe bilateral eye disease, with poor vision (Table 2). The patient must understand that there may be need for numerous visits to the hospital in the perioperative period to ensure adequate control of IOP. It is important for full and detailed counselling over two or more consultations so that expectations for prognosis are accurate.

\section{Operative problems}

PKP is technically more difficult in patients with congenital glaucoma because the corneas and the entire globe are larger than normal, and there may be extensive conjunctival and corneal scarring from previous surgery. During surgery a scleral supporting ring is required. The larger donor grafts can affect graft survival; peripheral vascularization will increase the likelihood of graft rejection. Recipient host diameter measurements were not recorded, although this could be useful to know with respect to the graft diameter and the proportional area of endothelium transplanted. Occasionally, the corneal surgeon may encounter a smaller than normal eye, which may also be technically demanding.

\section{Postoperative problems}

The majority of postoperative problems are related to IOP control. Accurate assessment of the IOP may be difficult or impossible using standard Goldmann applanation tonometry because of irregularity of the corneal surface. Inaccurate measurements may also arise because of altered corneoscleral rigidity. In this instance, measuring IOP using different techniques (digital, Tono-Pen, applanation) gives a better overall picture of the true IOP.

Postoperative-raised IOP occurred in four patients, two of which resulted in graft failure. In this scenario of uncontrolled IOP after PKP, cyclodiode laser is beneficial $^{5}$ and one of the four responded very well to it. For long-term management, tube drainage is useful although this should be carried out before PKP. In our study, one of the graft failures was in a patient (no. 5) who underwent exploration of a tube after PKP. In another, graft failure was made worse by infection around the tube causing endophthalmitis, although in this case survival was as long as 41.4 months.

We suggest that a glaucoma surgeon be involved from the planning stage. If the IOP is not adequately controlled on topical or systemic treatment then any drainage procedure should be carried out before PKP and the pressure stabilized. Following PKP, the glaucoma surgeon should again be involved in monitoring especially if drainage tubes are used so that with timely intervention pressure problems can be averted and graft survival optimized.

\section{Outcomes}

There was profound pre-existing bilateral eye disease in all patients in this study (Table 2). Complete visual loss and persistent inflammation and pain may require enucleation or evisceration. Our series is similar to the Huang $e t \mathrm{al}^{3}$ study of eight patients undergoing PKP, of whom $50 \%$ had the ungrafted eye enucleated compared to $44 \%$ in ours.

Overall, our results compare favourably with the only other published series of such patients ${ }^{3}$ in terms of both visual outcome and complications. In their study, seven out of eight had postoperative pressure problems, four of whom needed further glaucoma surgery. The differences may be for a variety of reasons. Modern techniques of storage of donor material enhance graft survival. The operations in our series were performed by one surgeon compared to three different surgeons in the Huang et al study, who also tended to use larger graft sizes.

Furthermore, cyclodiode laser was not widely available in 1989; it seems to have less side effects than surgical procedures or cyclocryotherapy for post-PKP reduction of IOP. 5 
Although the final visual acuities obtained in our series (Table 3) may seem disappointing by some standards, several aspects should be considered. First, many eyes undergoing PKP are severely damaged preoperatively, so that the initial visual acuity is very poor (finger counting or less). In these cases, the eye would have had no useful vision without surgery. A postoperative visual acuity of 6/60 may allow patients with severe bilateral problems to ambulate and care for themselves, whereas they would have been unable to do so without surgery. Second, even an oedematous graft that might be classified as a failure may provide better visual acuity than the patient's original cornea. Improvement in ambulation, communication, and behaviour is often noticeable, even when a graft appears to be opaque and there is no measurable improvement in visual acuity. ${ }^{6}$ Hence in patients with very poor vision and an opaque graft, there is a role for regrafting. Three patients in our series had multiple grafts (no.s 2, 6 and 8) and in only one did the second graft fail.

The Kaplan-Meir survival plot suggests that the probability of survival is relatively poor, however, a significant number of grafts have limited follow-up. With time a higher proportion of grafts of this kind are expected to survive as suggested by the Australian Corneal Graft Registry Report 1996.' They grouped grafts due to congenital glaucoma (of which there were only four) with grafts for congenital abnormalities, totalling 28. The follow-up period for the longest surviving graft was almost double than ours and more of their grafts had been followed up for a longer period.

\section{Conclusion}

Despite multiple impediments to good postoperative vision including previous surgery and pre-existing glaucomatous damage, a successful outcome can be achieved by careful patient selection, and an awareness of, and meticulous attention to postoperative complications. It is essential that the preoperative IOP control is as good as possible. A full and detailed counselling process is necessary for the patient to have a realistic idea of the visual prognosis and the possible risks. For the best possible outcome, corneal graft surgery in patients with congenital glaucomas should be performed in centres with a multidisciplinary input and by surgeons with a high level of expertise in these cases.

\section{References}

1 Spencer WH, Ferguson Jr WJ, Shaffer RN, Fine M. Late degenerative changes in the cornea following breaks in Descemet's membrane. Trans Am Acad Ophthalmol Otolaryngol 1966; 70: 973.

2 Schanzlin DJ, Goldberg DB, Brown SI. Transplantation of congenitally opaque corneas. Ophthalmology 1980; 87: 1253-1264.

3 Huang SC, Soong HK, Brenz RM, Meyer RF, Sugar A. Problems associated with penetrating keratoplasty for corneal edema in congenital glaucoma. Ophthalmic Surg 1989; 20(6): 399-402

4 Mc G Steele AD, Kirkness CM. Manual of Systematic Corneal Surgery. Butterworth Heinemann: Oxford, 1999.

5 Shah P, Lee GA, Kirwan JK, Bunce C, Bloom PA, Picker LA et al. Cyclodiode photocoagulation for refractory glaucoma after penetrating keratoplasty. Ophthalmology 2001; 108(11): 1986-1991.

6 Arffa RC, Stulting RD. Surgical management of corneal opacities in children. In Tasman W., Jaegar E.A., Lippincott J.B., (Eds), Philadelphia: Duane's Clinical Ophthalmology 4, Vol. 6, Chapter 106, 1997.

7 Williams KA, Muehlberg SM, Lewis RF, Giles LC, Coster DJ Australian Corneal Graft Registry Report 1996. Mercury Press: Adelaide, 1997, p 41. 